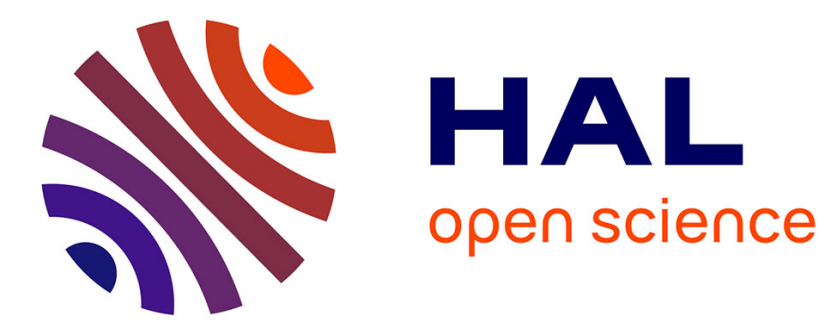

\title{
En librairie - 2006 - Numéro 2
}

- [.]revue Forestière Française, Rédaction

\section{- To cite this version:}

- [.]revue Forestière Française, Rédaction. En librairie - 2006 - Numéro 2. 2006, pp.192. 10.4267/2042/5819. hal-03534938

\section{HAL Id: hal-03534938 \\ https://hal.science/hal-03534938}

Submitted on 19 Jan 2022

HAL is a multi-disciplinary open access archive for the deposit and dissemination of scientific research documents, whether they are published or not. The documents may come from teaching and research institutions in France or abroad, or from public or private research centers.
L'archive ouverte pluridisciplinaire HAL, est destinée au dépôt et à la diffusion de documents scientifiques de niveau recherche, publiés ou non, émanant des établissements d'enseignement et de recherche français ou étrangers, des laboratoires publics ou privés. 


\title{
CHRONIOUE... EN LIBRAIRIE
}

\author{
GUILLARD (J.)
}

\section{Les forêts du rail}

Cahier d'Études, Forêt, Environnement et Société XVle-XXe siècle "Impact sur la forêt des axes et des moyens de circulation", $n^{\circ} 16,2006$, pp. 40-48.

Dans les relations entre les chemins de fer et les forêts - principalement dans les territoires plus ou moins tropicaux qui furent domaines de colonisation française - trois aspects sont à souligner :

1) Le problème des traverses, qui furent choisies longtemps majoritairement en bois tropicaux, mais aussi en métal (la préférence, dans certains cas, aux traverses métalliques étant due aux facilités d'approvisionnement, et aux influences politico-économiques des groupes métallurgiques). Mais vint un jour où le concurrent du bois ne fut plus l'acier, mais le béton, puis le béton pré-contraint..

2) La chauffe des locomotives à vapeur au bois (plutôt qu'au charbon). Fut un temps où le chemin de fer s'auto-approvisionnait sans contraintes, ni redevances, le long de la voie. Puis vinrent les permis de coupes de bois, comme aussi le système de la régie directe, mis en œuvre par les services forestiers qui n'oublièrent pas non plus la création de reboisements appelés parfois "les forêts du rail". Le problème cessa quand arrivèrent, de plus en plus nombreuses, les locomotives Diesel...

3) Les conséquences des problèmes forestiers... et leurs diverses solutions sur les forêts en général, et les services forestiers coloniaux. Création de réserves forestières, d'arboretum, de jardins d'essai, de plantations en savanes, etc. La période difficile 1940-1947 a bien souligné alors l'importance économique des forêts.

Jean PARDÉ

Adresse de l'éditeur : Institut d'Histoire moderne et contemporaine - Groupe d'Histoire des Forêts françaises - 45, rue d'Ulm - F-75005 PARIS.

CHABIN (J.-P.), textes réunis par

\section{La forêt dans tous ses états : de la Préhistoire à nos jours}

Besançon: Presses universitaires de Franche-Comté, 2005. - Annales littéraires, 785/24, 409 p. (ISBN 2-84867-108-4)

Prix : 25 euros

Ce livre réunit les actes du colloque de l'Association interuniversitaire de l'Est tenu à Dijon les 16 et 17 novembre 2001. Vingt-six contributions sont publiées pour éclairer trois états forestiers : la réalité, la perception, l'imaginaire. Onze articles traitent des réalités plurielles des sylvosystèmes appréhendés sur des pas de temps longs et ronds. Sept communications s'attachent à étudier les perceptions que l'on en a, allant de la vision satellitaire à la patrimonialisation des bois. Enfin, huit articles évoquent les représentations et les formes d'imaginaire suscitées (la forêt, espace sacralisé ; lieu de résistance ; endroit maléfique ; etc.).

Au total, cet ouvrage porté par un fil directeur historique rappelle que les interrogations formulées sur les forêts et leurs scénarii d'évolution sont et ont toujours été au cœur des débats de société.

Jean-Pierre HUSSON

Adresse de l'éditeur : Presses universitaires de Franche-Comté — 1, rue Claude Goudimel F-25200 BESANÇON. 